[Primer premio de la III Olimpiada de Filosofía organizada por FICUM, sección segundo de bachillerato]

\title{
¿Qué significa boy el término filosofía?
}

What does today the term "Philosophy" mean?

\author{
ADRIANA VITERI RECALDE \\ Colegio Patrocinio de San José (Estepona, España)
}

recibido: 14.06 .2015

aceptado: 26.07 .2015

\section{RESUMEN}

Este trabajo es el ganador de la III Olimpiada de Filosofía que organiza FICUM en la modalidad de primero de bachillerato. A los alumnos se le hizo la siguiente pregunta: ¿cuál es la filosofía del siglo XXI? Adriana, ha afrontado la cuestión comentado la importancia de recuperar la pasión por pensar las cosas con profundidad filosófica.

\section{PALABRAS CLAVE \\ FILOSOFÍA, PASIÓN, PENSAR, PROFUNDIDAD}

\begin{abstract}
This work is the winner of the III Olympiad of Philosophy that FICUM organized in the section "high school I". Students were asked the following question: what is the philosophy of the XXI century? Adriana, has discusses about the importance of recovering the passion for thinking with philosophical depth.
\end{abstract}

KEY WORDS

PHILOSOPHY, PASSION, THINK, DEPTH

Claridades. Revista de filosofía, 7 (2015), pp. 145-149

ISSN: 1889-6855 ISSN-e: 1989-3787 Dl.: PM 1131-2009

Asociación para la promoción de la Filosofía y la Cultura (FICUM) 
¿QUÉ PODER DECIR A CERCA DE LA FILOSOFÍA que hoy en día podemos encontrar por el mundo, por la calles, en nuestras maniacas mentes? Pienso y pienso, y vuelvo a pensar. A lo largo de la historia hemos estudiado la filosofía como tal, con su siguiente definición:

"La filosofía es el modo de saber de todos los seres por sus causas últimas, mediante algo llamado razón. Etimológicamente proviene del latín: phylosophía y del griego: phylos (amor, como tendencia) y sophía (sabiduría, ésta la cual nos lleva a preguntarnos por nuestras ultimidades, las cuestiones sobre la vida que ansiamos conocer)."

Hay algo que tenemos claro tras saber lo que ésta significa. Filosofías hay de todo lo que existe en esta vida, pero nunca podremos llegar a conocerlo todo de todo. Con nuestra razón, con los conocimientos que se nos dan, con lo que aprendemos, lo que vemos, lo que sentimos, aquello que intuimos y eso que nos hace llegar a ciertas conclusiones, todo esto y mucho más es lo que nos lleva a crear filosofías de vida, nos lleva a imaginar cómo es todo, como creemos de que se trata este lugar en el que nos encontramos.

A medida que ha ido pasando el tiempo desde sus inicios hasta el día de hoy, han pasados grandes filósofos, tales como Aristóteles, Platón, Kant, Sócrates... tanto como otros que han pasado más desapercibidos, otros que ni si quiera han sido reconocidos y muchos más que quedan por aparecer para darnos nuevas explicaciones del porque estamos aquí, para qué estamos aquí, o para explicarnos simplemente cual es la nueva forma de ver el mundo desde un punto de vista subjetivo u objetivo.

Resulta que la filosofía que hemos ido estudiando, ha ido cambiado, ya sea por la época, por el filósofo, o por que toca que en el transcurso de la vida exista una evolución, necesaria, para no quedarnos estancados en un único pensamiento. La filosofía evoluciona junto con las nuevas generaciones. Aunque que no quepa duda que siempre quedarán aquellos los cuales tengas sus ideales de vida claros y se queden con las ya vistas, más racionales para cada uno, dependiendo de cómo veamos nuestro alrededor, de cómo veamos como es este mundo, como funciona y como reaccionamos a medida que pasa y pasa el tiempo.

Somos personas hechas de una pasta, una pasta que tiene como ingrediente esencial aquello que se nos ha sido dado desde el momento en el que nacemos, tanto así como el ingrediente básico que va a hacer que esta pasta se vaya moldeando una vez vamos creciendo y creciendo y añadiendo a nuestra vida esos condimentos para al final darle un sabor,

Claridades. Revista de filosofía 7 (2015) 
un sabor que es lo que nosotros llamamos el ser de cada uno. Estoy hablando de todo lo que nos ocurre desde que nacemos hasta que morimos y que es lo que nos hace ser las personas que somos, es lo que nos hace convertirnos en aquello que deseamos, es lo que nos hace ser personas únicas. Personas únicas que llegaremos a alcanzar nuestras ultimidades, que lograremos atrapar y establecer en nosotros eso que llamamos filosofía.

Después de alguna manera u otra intentando captar lo que podemos tomar como lo que es la filosofía, adentrémonos en la realidad, adentrémonos un poco más a fondo en ese saber insaciable del hombre sobre la vida y sobre el pensamiento y razonamiento del ser humano.

Estamos dejando atrás el pensar, el utilizar la coherencia y el reflexionar con respecto a lo que sucede el día a día, a lo que pasa en nuestro entorno, a lo que ocurre en el mundo. Algo que nos está poco a poco llevando a un eslabón de una humanidad inhumana, la que cual se sacia con el poder, con el tener, con el conformarse. Se deja atrás el buscar, el captar, el reconocer, el aceptar la realidad, el ver más allá de lo visto. La filosofía, como aquello que se pregunta por el porqué de la vida, como aquello que busca alcanzar sus metas a través de sus conocimientos, ésta por desgracia va quedando más y más en el olvido. Las personas que piensan, los filósofos que se retuercen la cabeza intentando hallar soluciones, o tan sólo razones para ver cómo seguir subsistiendo rodeados de gente que no siente, que no profundiza, gente que se queda estancada y conforme con tener lo que todos tienen, que nos ansían más que establecerse para empantanarse y quedarse como seres mórbidos que cuando llegan a algo no vean la necesidad de buscar algo mejor.

Se está empezando a anteponer el placer a la razón. En el siglo XXI, qué es en el que estamos, la razón, lo que viene a ser el medio para llegar a la filosofía lo utilizamos para las cosas que nos llaman la atención por su atractivo, para agarrar, para llegar hasta lo que nos proporciona un placer, no intelectual, sino un placer físico, un placer emocional. Buscamos pero no para aprender, tampoco para saber, sino para tener, para disfrutar. Cierto por una parte es también, la razón es la que nos guía por el camino a todo lo que queremos. Pero principalmente está para llegar a algo lo cual nos satisfaga de manera que aporte en nuestra vida una mayor sabiduría para así lograr lo que realmente deseamos.

Como he dicho anteriormente cada uno de nosotros forma parte de una naturaleza que le ha sido dada al igual que forma parte de aquello 
que dejamos en manos del hombre para crearse a sí mismo en base a sus experiencias y conocimientos adquiridos. Pero resulta que otra de las razones por las que actualmente estamos perdiendo la filosofía es porque no aceptamos que somos lo que somos en cierto modo porque se no ha sido dado, sino que lo evitamos, optamos por tomar aquel camino directo en el que yo hago lo que yo quiero hacer para lograr lo que quiero, sin pensar que hay de más. No logramos alcanzar con nuestra inteligencia aquello que es virtuoso en nosotros. Con la inteligencia lo que hacemos a día de hoy es destruirnos a nosotros mismos, queremos el control de todo. Cuando en realidad ésta debería servirnos para pensar, conocer, controlar sabiendo controlar, y de esta forma dando un sentido a la vida, dándole el por qué a nuestras actuaciones y a la razón por las que nos movemos.

Yo podría decir que la filosofía para mi es pasión, otra forma de ver la vida y querer conocerla a fondo, con todo su esplendor. Conocer y cada uno de los detalles que ella está dispuesta a ofrecernos, que nos da en cada momento y que no vemos, porque sí, miramos, pero no vemos, no nos fijamos en cada pequeña particularidad de cada objeto, de cada ráfaga de conocimientos que se nos muestra.

La filosofía de estar metido en cuatro paredes, sentado en un sofá, delante de una pantalla, del que hagan y yo ya haré, o la filosofía de aquel que no aspira a nada, dejando pasar la vida. No aprovechando todo lo que se nos presenta en bandeja de plata.

Se no da todo hecho, no nos hace falta pensar y descubrir cuando tenemos tecnología que nos lo enseñan todo porque así no nos hacen aprender, nos dan la información, la recogemos para luego volver a desecharla tranquilamente sabiendo que siempre tendremos ese auxilio que es algo que ya está hecho. Lo que nos lleva a que nuestra finalidad sea crear más artilugios los cuales nos den todo masticado.

No necesitamos una filosofía tal cual era en tiempos pasados, donde la gente re rompía la crisma para darle sentido a nuestra existencia. Ahora es el hombre junto con la ciencia quien manda sobre nosotros, quien nos lleva a nuestra finalidad.

Por gran desgracia, de este modo coartándonos de nuestra propia libertad de elección a querer saber, porque nos convertimos en personas vagas, ineptas que siguen buscando que se le dé la comida como a pájaro en boca, sin hacer esfuerzo, para luego relevar a estos que nos hacen ser así, hasta que llegue el día en el que la filosofía se convierta en aquello de 
lo que se hablaba, de lo que se discutía y de lo que se conseguía darle cuerda a la vida. Y qué pena es decir que se hable así hoy en día de la filosofía.

Adriana Viteri ReCAlDe es alumna del primero de bachillerato del Colegio Patrocinio de San José (Estepona, España). Este trabajo que aquí publicamos es el ganador de la III Olimpiada de Filosofía organizada por FICUM, en la sección de primero de bachillerato.

Lineas de investigación:

Publicaciones recientes:

Dirección electrónica: palomagbriones@gmail.com 